\title{
Sliding Mode Control for Bearingless Induction Motor Based on a Novel Load Torque Observer
}

\author{
Zebin Yang, ${ }^{1}$ Ling Wan, ${ }^{1}$ Xiaodong Sun, ${ }^{2}$ Lin Chen, ${ }^{1}$ and Zheng Chen ${ }^{1}$ \\ ${ }^{1}$ School of Electrical and Information Engineering, Jiangsu University, Zhenjiang 212013, China \\ ${ }^{2}$ Automotive Engineering Research Institute, Jiangsu University, Zhenjiang 212013, China \\ Correspondence should be addressed to Xiaodong Sun; xdsun@ujs.edu.cn
}

Received 11 June 2016; Revised 26 August 2016; Accepted 6 September 2016

Academic Editor: Rafael Morales

Copyright (c) 2016 Zebin Yang et al. This is an open access article distributed under the Creative Commons Attribution License, which permits unrestricted use, distribution, and reproduction in any medium, provided the original work is properly cited.

\begin{abstract}
For the problem of low control performance of Bearingless Induction Motor (BIM) control system in the presence of large load disturbance, a novel load torque sliding mode observer is proposed on the basis of establishing sliding mode speed control system. The load observer chooses the speed and load torque of the BIM control system as the observed objects, uses the speed error to design the integral sliding mode surface, and adds the low-pass filter to reduce the torque observation error. Meanwhile, the output of the load torque is used as the feedforward compensation for the control system, which can provide the required current for load changes and reduce the adverse influence of disturbance on system performance. Besides, considering that the load changes lead to the varying rotational inertia, the integral identification method is adopted to identify the rotational inertia of BIM, and the rotational inertia can be updated to the load observer in real time. The simulation and experiment results all show that the proposed method can track load torque accurately, improve the ability to resist disturbances, and ameliorate the operation quality of BIM control system. The chattering of sliding mode also is suppressed effectively.
\end{abstract}

\section{Introduction}

Based on the similarity principles of magnetic bearing and alternating current (AC) motor stator structure, BIM is formed. Two sets of windings are embedded in the stator slot of BIM, which can separately produce electromagnetic torque and radial levitation force. BIM achieves the integration of rapid rotation and stable suspension of rotor by changing the currents in the windings and avoids the mechanical bearing friction, wear and tear, and lubrication. It breaks the bottleneck of traditional asynchronous motor developing towards the higher precision and higher speed direction [15]. BIM has many better advantages than the traditional asynchronous motor, such as simple structure, uniform air gap, high mechanical strength, high speed, and ultrahigh speed running in the corrosion or other special environments. Therefore, it shows broad development prospect in medical equipment, transportation, national defense, and so forth [69]. However, BIM has the characteristics of nonlinearity, multivariability, and strong coupling. The traditional PI controller cannot acquire high-performance control for BIM when the control system is disturbed by load torque [10].

Sliding mode variable structure control, as a kind of special nonlinear control, can operate in accordance with the trajectory designed by people and purposefully adjust operation according to the system status, which can gain excellent control performance. Due to the fact that the sliding mode control not only can be set by people, but also does not need high precision mathematical model and has strong robustness to disturbances, it is becoming a hot research topic [11-15], and it is gradually applied in the AC servo system. In [16], a new reaching law was designed to improve the operation quality of sliding mode. At the same time, it was applied in the speed control, which effectively enhanced the robustness of permanent magnet synchronous motor (PMSM) system. In [17], the sliding mode control combining with model reference adaptive was used to obtain the speed. The results showed that it increased the estimation precision of rotor velocity for PMSM and decreased the chattering. In [18], the sliding mode control was used in a generator based 
on the exercise equipment with nonlinear $P-V$ characteristic curves. The amount of generator input current harmonic is greatly reduced. In [19], the conventional sliding mode control was united with the adaptive fuzzy backstepping scheme. The simulation proved that this method improved the performance of mismatched uncertain system. In [20], the sliding mode control dealt with the difficult problem of obtaining the counterelectromotive force, and it finally implemented the direct torque control of brushless direct current motor. In [21], the sliding mode control was used to detect the speed and position for PMSM. The experimental results proved the validity of the proposed sliding mode observer. In [22], based on the nonsingular terminal sliding mode algorithm and backstepping method, the sliding mode observer and position controller were put forward, which can estimate the torque accurately and track the position quickly. In [23], the adaptive sliding mode control for uncertain singularly perturbed nonlinear system was designed. It not only reduced the effects of uncertainty, but also guaranteed the control performance. In $[24,25]$, the load sliding mode observers were proposed. They diminished the adverse effects of load changes on PMSM and improved the antidisturbance ability of controlled system at some level. However, they all ignored the problem that the load changes result in the different rotational inertia and the controlled system had large chattering. Hence, the system cannot achieve the best dynamic performance.

A novel sliding mode observer of load torque, of which the state variables are the speed and load torque, is proposed to suppress the impacts of the load torque changes on BIM control system. A low-pass filter used in the observer reduces the observation error of torque. Moreover, the observer as feedforward compensation for the given current alleviates the output pressure of sliding mode controller (SMC). In addition, adopting the integral identification method validly identifies the rotational inertia and improves the precision of BIM. The simulation and experimental results show that the proposed method overcomes the disadvantageous effects on the speed regulation system generated by load disturbances and strengthens the antidisturbance ability of the system.

\section{The Dynamics Model of BIM}

According to the electromagnetic field theory, the radial levitation force of BIM in the $d-q$ coordinates can be established as [6]

$$
\begin{aligned}
& F_{x}=K\left(\psi_{1 d} i_{s 2 d}+\psi_{1 q} i_{s 2 q}\right), \\
& F_{y}=K\left(\psi_{1 d} i_{s 2 q}-\psi_{1 q} i_{s 2 d}\right),
\end{aligned}
$$

where $K=K_{m}+K_{l}, K_{m}=\pi P_{1} P_{2} L_{m 1} / 18 \operatorname{lr} \mu_{0} N_{1} N_{2}$, and $K_{l}=P_{1} N_{2} / 2 r N_{1} ; F_{x}$ and $F_{y}$ are the components of the radial levitation force in $x$ and $y$ directions; the subscript " 1 " represents the torque windings, the subscript " 2 " represents the radial levitation force windings, " $s$ " represents the stator, and " $r$ " represents the rotor; $P_{1}$ and $P_{2}$ separately represent the pole pairs of torque windings and suspension windings; $i_{s 2 d}$ and $i_{s 2 q}$ are the current components of the stator in levitation force windings under the $d-q$ axis; $L_{m 1}$ is mutual inductance of the levitation force windings; $l$ is the effective length of the rotor; $r$ is the stator inner diameter; $\mu_{0}$ is the permeability of vacuum; $N_{1}$ and $N_{2}$, respectively, show the effective number of turns of the torque windings and the levitation force windings; and $\psi_{1 d}$ and $\psi_{1 q}$ are the components of flux linkage for the torque winding in the $d$ - $q$ coordinates, respectively.

With the torque windings and the levitation force windings, BIM is a nonlinear, strongly coupled, and complex system. In order to simplify the analysis of BIM, a hypothesis is given that the levitation force windings only create a rotating magnetic field. The rotor voltage equation can be described as

$$
\begin{aligned}
u_{r 1 d} & =R_{r 1} i_{r 1 d}+p \psi_{r 1 d}-\left(\psi_{1 q}+L_{r 1 l} i_{r 1 q}\right)\left(\omega_{1}-\omega_{r}\right) \\
& =0, \\
u_{r 1 q} & =R_{r 1} i_{r 1 q}+p \psi_{r 1 q}-\left(\psi_{1 d}+L_{r 1 l} i_{r 1 d}\right)\left(\omega_{1}-\omega_{r}\right) \\
& =0,
\end{aligned}
$$

where $u_{r 1 d}$ and $u_{r 1 q}$ are the rotor voltages of torque windings in $d$ - $q$ coordinates; $R_{r 1}$ is the rotor resistance; $\omega_{1}$ and $\omega_{r}$ are separately the air gap field speed and rotor speed; and $p$ is the differential operator.

The flux linkage can be expressed as

$$
\begin{aligned}
& \psi_{1 d}=\left(i_{s 1 d}+i_{r 1 d}\right) L_{m 1}, \\
& \psi_{1 q}=\left(i_{s 1 q}+i_{r 1 q}\right) L_{m 1}, \\
& \psi_{s 1 d}=\psi_{1 d}+i_{s 1 d} L_{s 1 l}, \\
& \psi_{s 1 q}=\psi_{1 q}+i_{s 1 q} L_{s 1 l}, \\
& \psi_{r 1 d}=\psi_{1 d}+i_{r 1 d} L_{r 1 l}, \\
& \psi_{r 1 q}=\psi_{1 q}+i_{r 1 q} L_{r 1 l},
\end{aligned}
$$

where $L_{s 1 l}$ and $L_{r 1 l}$ are the stator leakage inductance and rotor leakage inductance of torque windings, respectively.

The electromagnetic torque equation is set up as

$$
T_{e}=P_{1}\left(\psi_{1 d} i_{s 1 q}-\psi_{1 q} i_{s 1 d}\right)
$$

The equation of motion is written as

$$
T_{e}=T_{L}+\frac{J}{P_{1}} p \omega_{r},
$$

where $T_{L}$ is the load torque and $J$ is the rotational inertia.

After coordinate transforming, the rotor flux in $d-q$ axis can be expressed as

$$
\begin{aligned}
& \psi_{r 1 d}=L_{m 1} i_{s 1 d}+L_{r 1} i_{r 1 d}, \\
& \psi_{r 1 q}=L_{m 1} i_{s 1 q}+L_{r 1} i_{r 1 q} .
\end{aligned}
$$


Making the axis of the rotating coordinates $d$ coincide with the rotor flux linkage of torque windings, it is written as $\psi_{r 1 d}=\psi_{r 1}$. Formula (6) can be simplified as

$$
\begin{aligned}
& i_{r 1 d}=\frac{\psi_{r 1}-L_{m 1} i_{s 1 d}}{L_{r 1}}, \\
& i_{r 1 q}=-\frac{L_{m 1}}{L_{r 1}} i_{s 1 q} .
\end{aligned}
$$

Putting Formula (7) into Formula (2), the excitation current $i_{s 1 d}$ and slip speed $\omega_{s}$ can be obtained as follows:

$$
\begin{gathered}
i_{s 1 d}=\frac{T_{r 1} p+1}{L_{m 1}} \psi_{r 1}, \\
\omega_{s}=\frac{L_{m 1}}{T_{r 1} \psi_{r 1}} i_{s 1 q},
\end{gathered}
$$

where $\omega_{s}=\omega_{1}-\omega_{r}$ and $T_{r 1}=L_{r 1} / R_{r 1}$ is the time constant of rotor.

The electromagnetic torque equation turns into

$$
T_{e}=P_{1} \frac{L_{m 1}}{L_{r 1}} i_{s 1 q} \psi_{r 1}
$$

where $L_{r 1}$ is the rotor self-induction. Figure 1 is the block diagram of rotor field-oriented decoupling control.

\section{The Speed SMC of BIM}

The system state variables are defined as

$$
\begin{aligned}
& e_{\omega 1}=\omega^{*}-\omega, \\
& e_{\omega 2}=e_{\omega 1}^{\prime}=-\omega^{\prime},
\end{aligned}
$$

where $\omega^{*}$ is the given speed and $\omega$ is the actual speed.

After combining with (5), Formula (10) is described as

$$
\begin{aligned}
& e_{\omega 1}^{\prime}=e_{\omega 2}=-\frac{P_{1}^{2} \psi_{r 1}}{J} \frac{L_{m 1}}{L_{r 1}} i_{s 1 q}+\frac{P_{1}}{J} T_{L}, \\
& e_{\omega 2}^{\prime}=e_{\omega 1}^{\prime \prime}=-\frac{P_{1}^{2} \psi_{r 1}}{J} \frac{L_{m 1}}{L_{r 1}} i_{s 1 q}^{\prime} .
\end{aligned}
$$

The sliding mode surface is chosen as

$$
s=e_{\omega 1}+c_{1} e_{\omega 2} .
$$

This paper chooses the reaching law [16] to weaken the inherent chattering:

$$
\begin{aligned}
& \frac{d s}{d t}=-\varepsilon|X|^{2} \operatorname{sgn}(s)-k|X|^{2} s, \\
& \quad \lim _{t \rightarrow \infty}|X|=0, a \geq 0, \quad b \geq 0, \varepsilon>0, k>0 .
\end{aligned}
$$

According to the Lyapunov stability theory, the existence condition of generalized sliding mode is written as [12]

$$
V=\frac{1}{2} s^{2}<0
$$

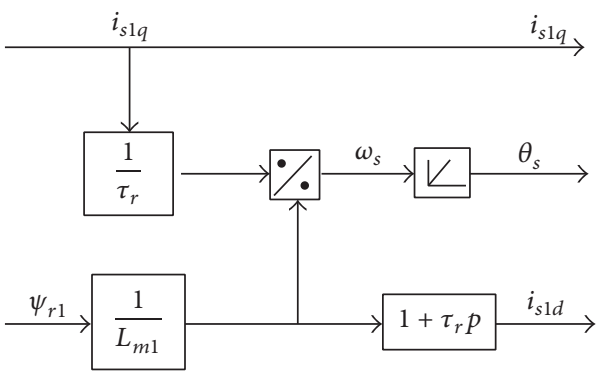

FIGURE 1: Rotor field-oriented decoupling control.

Differentiating (14) with respect to time, it becomes (15) by substituting (13):

$$
\begin{aligned}
\dot{V} & =s \dot{s}=s\left(-\varepsilon|X|^{2} \operatorname{sgn}(s)-k|X|^{2} s\right) \\
& =-\varepsilon|X|^{2}|s|-k|X|^{2} s^{2}<0 .
\end{aligned}
$$

Formula (15) always stands up. Hence, the system can arrive at sliding mode surface in limited time.

Differentiating $s=e_{\omega 1}+c_{1} e_{\omega 2}$ with respect to time, it can be gained as

$$
s^{\prime}=e_{\omega 1}^{\prime}+c_{1} e_{\omega 2}^{\prime}=e_{\omega 2}-\frac{c_{1} P_{1}^{2} \psi_{r 1} L_{m 1}}{J L_{r 1}} i_{s 1 q}^{\prime} .
$$

Combining Formula (13) with Formula (16) gives the following formula:

$$
e_{\omega 2}-\frac{c_{1} P_{1}^{2} \psi_{r 1} L_{m 1}}{J L_{r 1}} i_{s 1 q}^{\prime}=-\varepsilon|X|^{2} \operatorname{sgn}(s)-k|X|^{2} s .
$$

Choosing $X=e_{\omega 1}$ to avoid the differential interference in $e_{\omega 2}$, the sliding mode controller is designed as

$$
\begin{aligned}
i_{s 1 q}= & \frac{J L_{r 1}}{P_{1}^{2} \psi_{r 1} L_{m 1} c_{1}} \\
& \cdot \int\left(\varepsilon\left|e_{\omega 1}\right|^{2} \operatorname{sat}(s)+k\left|e_{\omega 1}\right|^{2} s+e_{\omega 2}\right) d t .
\end{aligned}
$$

From (18), it can be seen that the current can eliminate steadystate error and improve the accuracy of system.

\section{The Design of Novel Load Torque Sliding Mode Observer}

4.1. The Design of Load Torque Sliding Mode Observer. Considering the high switch frequency of the controller, the load torque can be deemed to be a constant value in a control cycle. Considering the load torque as an extension, the state equation of BIM can be expressed as

$$
\begin{aligned}
\frac{d \omega}{d t} & =\frac{P_{1}^{2} \psi_{r 1}}{J} \frac{L_{m 1}}{L_{r 1}} i_{s 1 q}-\frac{P_{1}}{J} T_{L}, \\
\frac{d T_{L}}{d t} & =0 .
\end{aligned}
$$


Based on the equation above, the extended load torque observer is written as

$$
\begin{aligned}
\frac{d \widehat{\omega}}{d t} & =\frac{P_{1}^{2} \psi_{r 1}}{J} \frac{L_{m 1}}{L_{r 1}} i_{s 1 q}-\frac{P_{1}}{J} \widehat{T}_{L}+V, \\
\frac{d \widehat{T}_{L}}{d t} & =\eta V,
\end{aligned}
$$

where $V=\gamma \operatorname{sgn}(\omega-\widehat{\omega}) ; \gamma$ is the sliding mode gain; $\eta$ is the feedback gain; and $\widehat{\omega}$ and $\widehat{T}_{L}$ are the estimations of electrical angular velocity and load torque, respectively.

The estimation errors of speed and the load are defined as

$$
\left[\begin{array}{l}
x_{1} \\
x_{2}
\end{array}\right]=\left[\begin{array}{c}
\omega-\widehat{\omega} \\
T_{L}-\widehat{T}_{L}
\end{array}\right] .
$$

After Formula (19) subtracts Formula (20), the observation errors of sliding mode are obtained as

$$
\begin{aligned}
& \frac{d x_{1}}{d t}=-\frac{P_{1}}{J} x_{2}-V, \\
& \frac{d x_{2}}{d t}=-\eta V .
\end{aligned}
$$

Because the torque change is expressed in the form of speed finally, the designed sliding mode surface consists of the state variable $x_{1}=\omega-\widehat{\omega}$. The sliding mode surface is established as (23) to reduce the system overshoot:

$$
s=x_{1}+c \int x_{1} d t .
$$

Differentiating the sliding mode surface and combining with (13) and (5), it can be acquired as

$$
\begin{aligned}
\widehat{T}_{L} & =\frac{J}{P_{1}}\left[\gamma \operatorname{sgn}(\omega-\widehat{\omega})-c(\omega-\widehat{\omega})-k|\omega-\widehat{\omega}|^{2} s\right. \\
& \left.-\varepsilon|\omega-\widehat{\omega}|^{2} \operatorname{sgn}(s)\right]+T_{L}(0) .
\end{aligned}
$$

Because the system load torque $T_{L}$ is an unknown variable, $T_{L}(0)$ is recorded as the estimation of load torque at time zero.

In order to decrease the chattering in the sliding mode, the sign function $\operatorname{sgn}(s)$ is replaced by saturation function sat $(s, \Delta)[25]$ :

$$
\operatorname{sat}(s, \Delta)= \begin{cases}1 & s_{i}(x)>-\Delta \\ \frac{s_{i}(x)}{\Delta} & -\Delta<s_{i}(x)<\Delta \\ -1 & s_{i}(x)<-\Delta .\end{cases}
$$

Formula (24) can be expressed as

$$
\begin{aligned}
\widehat{T}_{L} & =\frac{J}{P_{1}}\left[\gamma \operatorname{sat}(\omega-\widehat{\omega})-c(\omega-\widehat{\omega})-k|\omega-\widehat{\omega}|^{2} s\right. \\
& \left.-\varepsilon|\omega-\widehat{\omega}|^{2} \operatorname{sat}(s, \Delta)\right]+T_{L}(0) .
\end{aligned}
$$

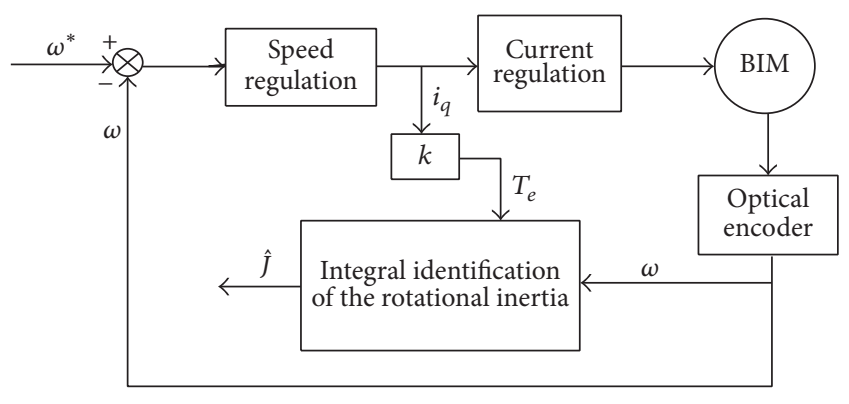

FIgURE 2: Diagram of inertia identification.

For the purpose of improving the observation precision of sliding mode observer, a low-pass filter [7] shown in (27) is added to the observer:

$$
\widetilde{T}_{L}=\frac{\omega_{c}}{s+\omega_{c}} \widehat{T}_{L}
$$

The output of load torque observer is as the feedforward disturbance compensation $i_{q 2}$ and the given current $i_{q}^{*}$ is described as

$$
\begin{aligned}
i_{q}^{*}= & i_{s 1 q}+i_{q 2} \\
= & \frac{J L_{r 1}}{P_{1}^{2} \psi_{r 1} L_{m 1} c_{1}} \int\left(\varepsilon\left|e_{\omega 1}\right|^{2} \text { sat }(s)+k\left|e_{\omega 1}\right|^{2} s+e_{\omega 2}\right) d t \\
& +\frac{\widetilde{T}_{L}}{\partial},
\end{aligned}
$$

where $\partial>0$ is the feedforward gain of torque observation.

From (18) and (28), it can be known that $\varepsilon$ and $k$ in Formula (18) need to be large enough for meeting the load disturbance, while large $\varepsilon$ and $k$ increase the amplitude of discrete magnitude and result in big chattering. However, in (28), the observed disturbance is used to provide the required current for disturbance changes and needs no large $\varepsilon$ and $k$. As a consequence, the feedforward compensation scheme of load torque reduces the gain amplitude of sliding mode and lowers the negative impacts on the control system caused by the disturbances.

4.2. The Load Torque Sliding Mode Observer with the Rotational Inertia Online Identification. When a sliding mode observer is designed, the rotational inertia of system is usually regarded as a known quantity. However, in practice application, the load changes will lead to the inertia changes. Therefore, identifying the inertia online and timely updating it to the observer will greatly improve the overall control performance of BIM system. With the characteristics of high precision and strong robustness, the integral identification algorithm is used to identify the rotational inertia online. The structure diagram of BIM's speed loop based on the integral identification is shown in Figure 2.

Equation (5) is rewritten as

$$
T_{e}=\frac{\widehat{J}}{P_{1}} \frac{d \omega}{d t}+\widehat{T}_{r}
$$


where $\widehat{J}$ is the estimation of rotational inertia and $\widehat{T}_{r}$ is the collection of disturbances and its specific expression is as follows:

$$
\widehat{T}_{r}(t)=\Delta J \frac{d \omega}{d t}+T_{L},
$$

where $\Delta J$ is the inertia error, $J-\widehat{J}=\Delta J$.

By the formula above, it can be found that the output of disturbance is in the form of torque. At the same time, observing torque can obtain $\Delta J$. Using $\Delta J$ and constant recursion correction based on selecting initial value of inertia, the recursion equation can be expressed as

$$
\widehat{J}(k)=\widehat{J}(k-1)+\Delta J .
$$

Thus, the identification accuracy of inertia depends on $\Delta J$. In order to obtain high accuracy $\Delta J$, this paper chooses a periodic speed signal and uses the integral to eliminate the influences of torque disturbances on rotational inertia.

Because of the high sample frequency, the load torque $T_{L}$ is regarded as $T_{L}(t)=T_{L}(t+T)$ and the speed signal $\omega$ meets $\omega(t)=\omega(t+T)$. After on both sides of Formula (30) multiplying by $\dot{\omega}(t)$ and integrating it, the equation is written as

$$
\begin{aligned}
\int_{(k-1) T}^{k T} \widehat{T}_{r}(t) \dot{\omega}(t) d t= & \Delta J \int_{(k-1) T}^{k T} \dot{\omega}^{2}(t) d t \\
& +\int_{(k-1) T}^{k T} T_{L}(t) \dot{\omega}(t) d t .
\end{aligned}
$$

Due to the fact that the load torque is a constant within a cycle, the definite integral of the load torque in (32) can be calculated as follows:

$$
\begin{aligned}
\int_{(k-1) T}^{k T} T_{L}(t) \dot{\omega}(t) d t & =\left.T_{L} \omega(t)\right|_{(k-1) T} ^{k T} \\
& =T_{L} \omega(k T)-T_{L} \omega((k-1) T) \\
& =0 .
\end{aligned}
$$

Hence, (32) can be simplified as

$$
\int_{(k-1) T}^{k T} \widehat{T}_{r}(t) \dot{\omega}(t) d t=\Delta J \int_{(k-1) T}^{k T} \dot{\omega}^{2}(t) d t .
$$

From (34), it can be found that the effects of load disturbance on the inertia have been solved.

Equation (34) can be expressed as

\begin{tabular}{|c|c|c|}
\hline Parameters & Torque winding & Suspension winding \\
\hline Rated power (Kw) & 1 & 0.5 \\
\hline Rated current (A) & 2.86 & 2.86 \\
\hline Stator resistance $(\Omega)$ & 2.01 & 1.03 \\
\hline Rotor resistance $(\Omega)$ & 11.48 & 0.075 \\
\hline $\begin{array}{l}\text { Mutual inductance of } \\
\text { stator and rotor }(\mathrm{H})\end{array}$ & 0.15856 & 0.00932 \\
\hline $\begin{array}{l}\text { Stator leakage } \\
\text { inductance }(\mathrm{H})\end{array}$ & 0.16310 & 0.01199 \\
\hline $\begin{array}{l}\text { Rotor leakage } \\
\text { inductance }(\mathrm{H})\end{array}$ & 0.16778 & 0.01474 \\
\hline $\begin{array}{l}\text { Rotational inertia } \\
\left(\mathrm{kg} \cdot \mathrm{m}^{2}\right)\end{array}$ & 0.00769 & 0.00769 \\
\hline Rotor mass (kg) & 2.85 & 2.85 \\
\hline $\begin{array}{l}\text { Stator inner diameter } \\
(\mathrm{mm})\end{array}$ & 98 & 98 \\
\hline Core length (mm) & 105 & 105 \\
\hline Pole pairs & 1 & 2 \\
\hline
\end{tabular}

$$
\Delta J=\frac{\int_{(k-1) T}^{k T} \widehat{T}_{r}(t) \dot{\omega}(t) d t}{\int_{(k-1) T}^{k T} \dot{\omega}^{2}(t) d t} .
$$

Combining with (35), the recursive equation of inertia identification is available as

$$
\widehat{J}(k)=\widehat{J}(k-1)+\frac{\int_{(k-1) T}^{k T} \widehat{T}_{r}(t) \dot{\omega}(t) d t}{\int_{(k-1) T}^{k T} \dot{\omega}^{2}(t) d t} .
$$

TABLE 1: Parameters of the Bearingless Induction Motor (BIM).

Inertia identification is realized and can be updated to the load observer automatically.

\section{Simulation and Experimental Research}

5.1. Results and Analysis of the Simulation. To validate the effectiveness of novel load torque observer with the function of inertia identification online and feedforward compensation scheme for BIM speed regulation system, a simulation mode of control system is constructed. The control block diagram of BIM includes two parts: the rotation part and the suspension part. In rotation part, the SMC outputs the given current $i_{q}^{*}$ by inputting the speed error. Combining with the given air gap flux $\psi_{1}^{*}$, the excitation component is received. With the coordinate transformation method, the two-phase excitation current is transformed into the three-phase given current. With the current regulation, the three-phase current is obtained which is used to control the rotation of rotor. In suspension part, the radial levitation force of BIM is output by PID controllers. With $\psi_{1}^{*}$, the current in the levitation windings can be calculated. By the coordinate transformation and current regulation, the required three-phase current is gained. The steady suspension and rapid rotation of rotor are realized finally. The whole control block diagram of BIM is shown in Figure 3 and the specific parameters of BIM are shown in Table 1.

In the simulation, the rotational inertia is set to $0.00769 / \mathrm{kg} \cdot \mathrm{m}^{2}$ and the given speed is $n=10000 \mathrm{r} / \mathrm{min}$. Based on the tracking characteristics of integral identification algorithm, a step signal is selected as the given speed whose amplitude is $10000 \mathrm{r} / \mathrm{min}$ and the sampling cycle is defined as $T=0.02 \mathrm{~s}$. Figure 4 shows the identification waveform of rotational inertia when the system suffers the load disturbances. It can be seen that the rotational inertia $J$ converges to the given value within a sampling period at first. When 


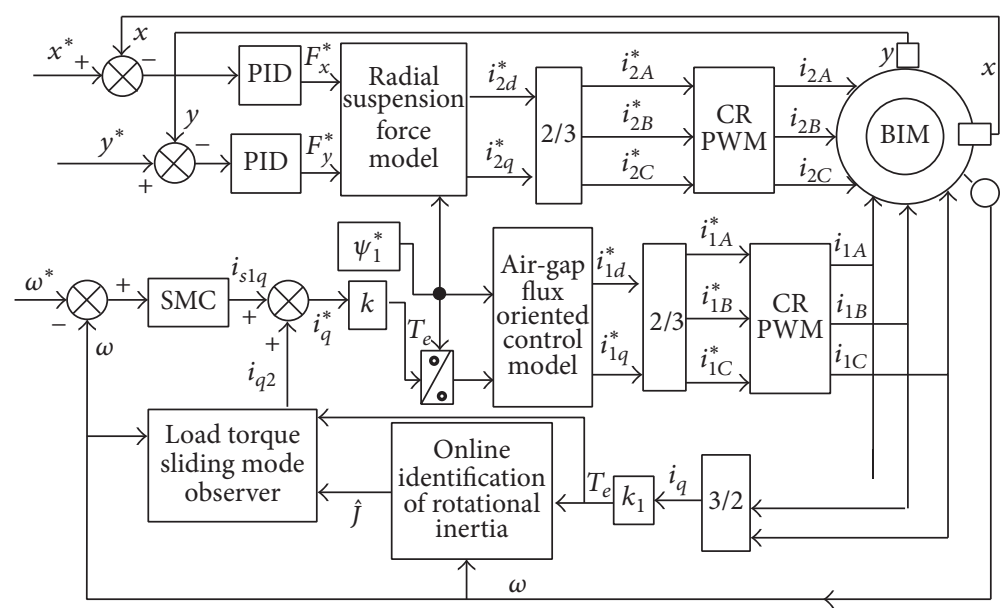

FIgURE 3: Control system diagram of Bearingless Induction Motor (BIM).

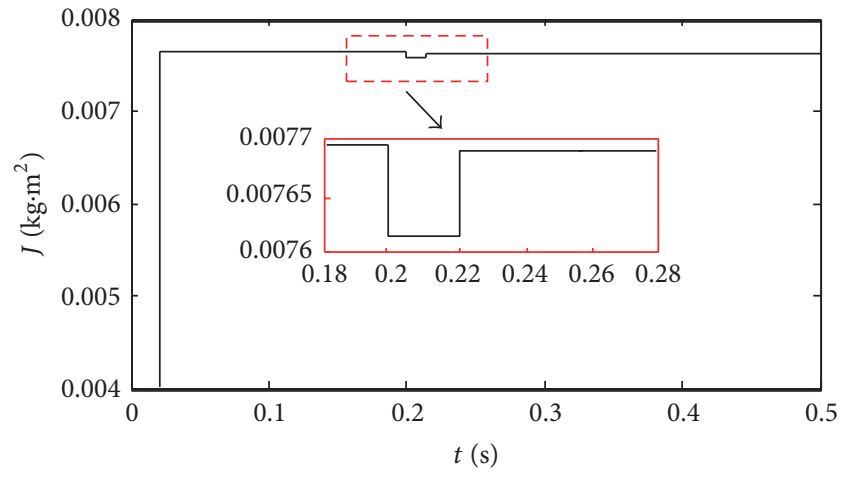

Figure 4: The identification result of rotational inertia.

the system is attacked by the load disturbance $(8 \mathrm{~N} \cdot \mathrm{m}), J$ just has small fluctuation and restores the stabilization quickly. Therefore, the integral identification algorithm has better tracking ability and shows good robustness for disturbance.

Figures 5(a) and 5(b) show the estimation load $\widehat{T}_{L}$ and the actual load $T_{L}$ under load mutation. As shown in (a) and (b), a sudden load $(8 \mathrm{~N} \cdot \mathrm{m})$ is added to the system at $t=0.4 \mathrm{~s}$. Then, the load drops to $0 \mathrm{~N} \cdot \mathrm{m}$ at $t=0.6 \mathrm{~s}$. It can be seen from Figure 5 that the sliding mode observer can accurately track the load torque and has strong robustness.

Figure 6 shows the simulations of BIM in the presence of sudden load $(8 \mathrm{~N} \cdot \mathrm{m})$. Figures $6(\mathrm{a})$ and $6(\mathrm{~b})$ present the output currents from the SMC and the load torque observer, respectively. Figure 6(c) shows the speed response of BIM under the proposed control strategy in this paper and the conventional SMC. Figure 6(a) shows that the current from SMC just slightly increases and it returns back to the stable value rapidly. Figure 6(b) indicates that the compensation current from load torque observer rises quickly, which provides enough current for disturbance. Figure 6(c) demonstrates that the speed of BIM controlled by the conventional SMC has larger fluctuation and needs more time to operate at the original speed value than the proposed method when it is attacked by load mutation. Based on the above analysis, the following two conclusions can be obtained:

(1) The feedforward compensation scheme of load torque observer can provide the required current for load changes. It can reduce the output pressure of SMC and make the output of SMC almost invariant.

(2) Based on the novel load observer and feedforward compensation strategy, the speed of BIM under big disturbance has no fluctuation and can quickly converge to the original value. The method weakens the system chattering effectively and enhances the stability of system.

Figures 7(a) and 7(b) show the rotor radial displacement at the speed of $n=10000 \mathrm{r} / \mathrm{min}$. It can be known that the rotor can arrive at the steady point rapidly with the proposed control strategy in this paper. It achieves the integration of rapid rotation and stable suspension. The system has excellent control performance.

5.2. Results and Analysis of the Experiment. In order to further verify the effectiveness of the proposed control method, an experimental prototype with two degrees of freedom is used to build experimental platform. Due to the limits of photoelectrical encoder measuring speed, the speed is set to $2000 \mathrm{r} / \mathrm{min}$ in the experiment. The air gap of motor auxiliary bearing is $0.4 \mathrm{~mm}$. Moreover, the load mutation is carried out to detect antijamming performance of BIM. The experimental results are shown in Figure 8.

Figure 8(a) shows the radial displacement when the system is controlled by the proposed method in this paper. The rotor is running around the equilibrium point and the maximum offset value is far less than the air gap of auxiliary bearing. It indicates that the rotor is suspended steadily under the proposed control strategy. Figures $8(\mathrm{~b})-8(\mathrm{e})$ show the responses of BIM with the load mutation. Figure $8(\mathrm{~b})$ gives the identification results of rotational inertia. In view of the excellent robustness of integral identification algorithm, the 


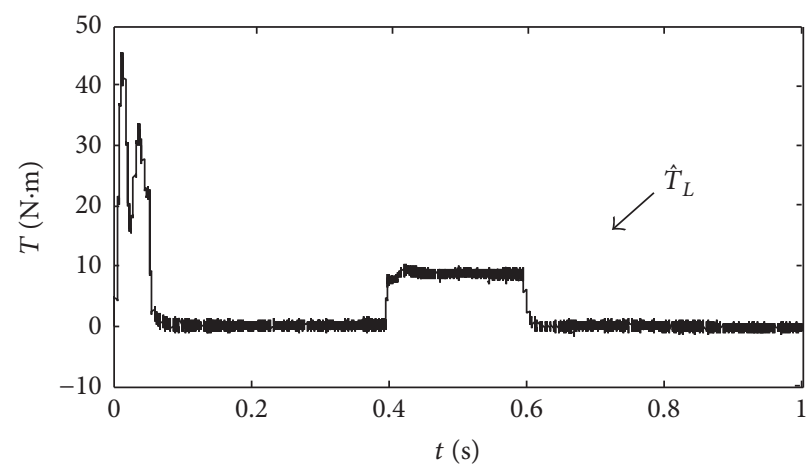

(a)

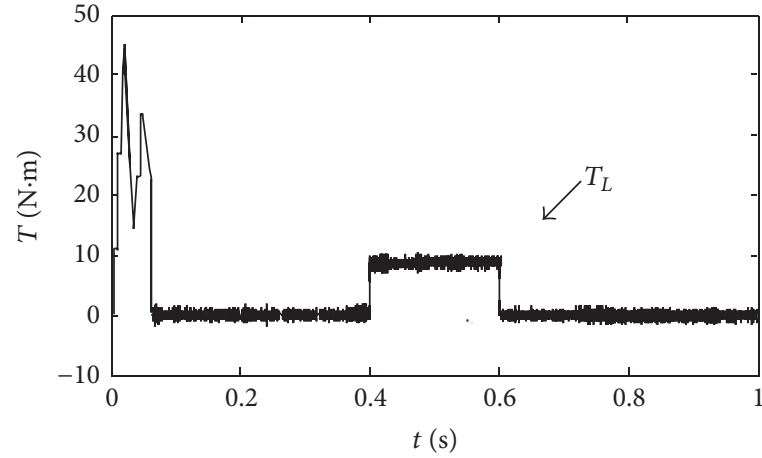

(b)

FIGURE 5: The torque waveforms under load mutation: (a) the waveform of the estimation torque; (b) the waveform of the actual torque.

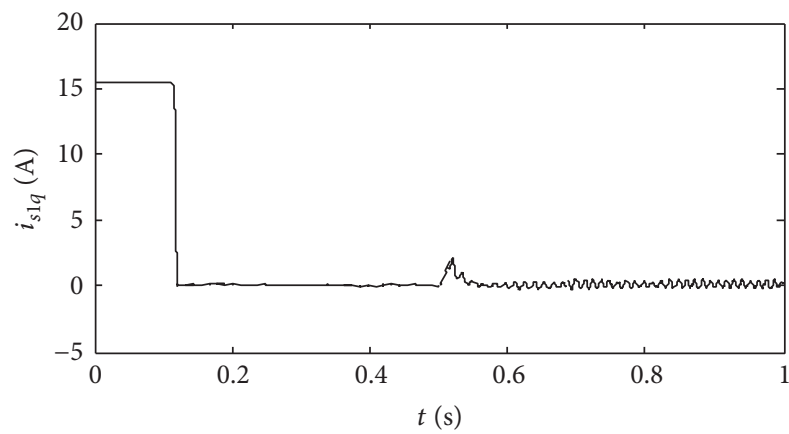

(a)

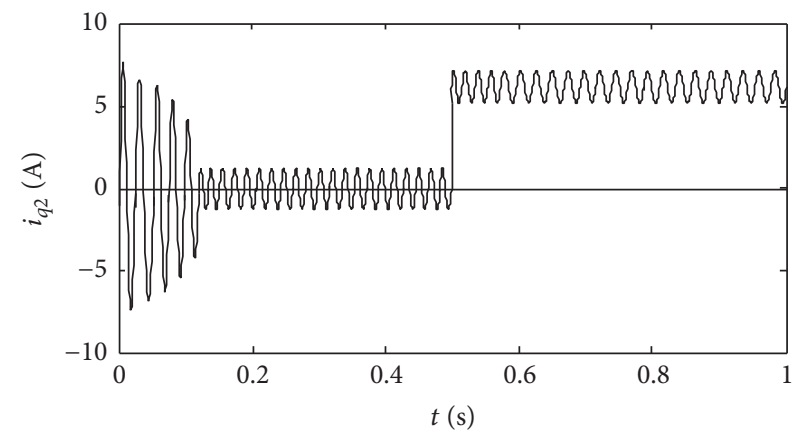

(b)

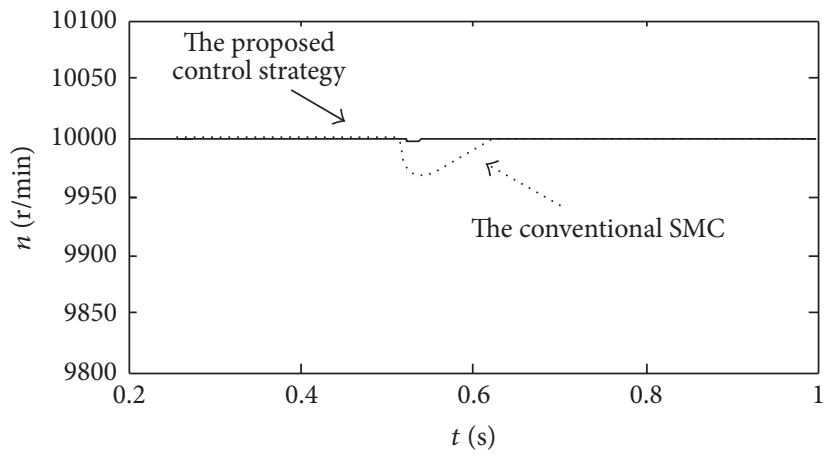

(c)

FIGURE 6: The responses of current and speed under load mutation: (a) the output current of SMC; (b) the compensation current of load torque; and (c) the speed response of BIM under sudden load.

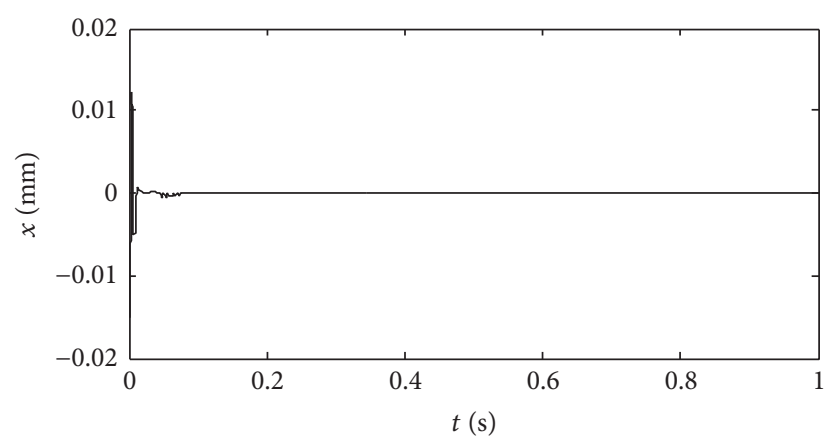

(a)

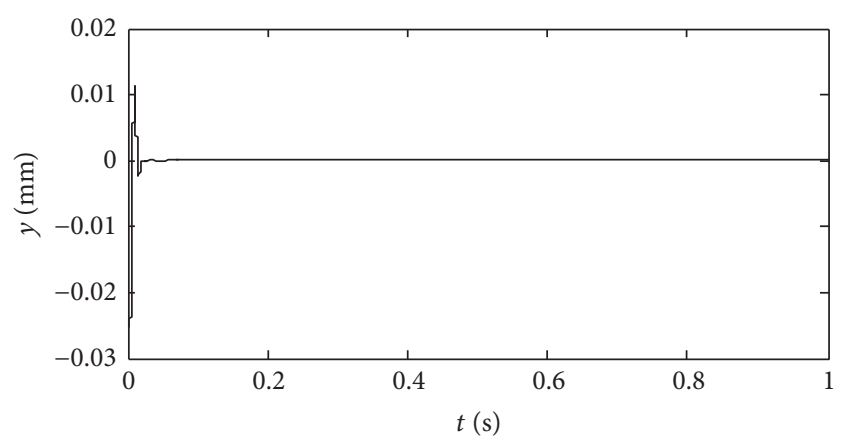

(b)

FigURE 7: Waveforms of rotor radial displacement: (a) the radial displacement on $x$-axis; (b) the radial displacement on $y$-axis. 


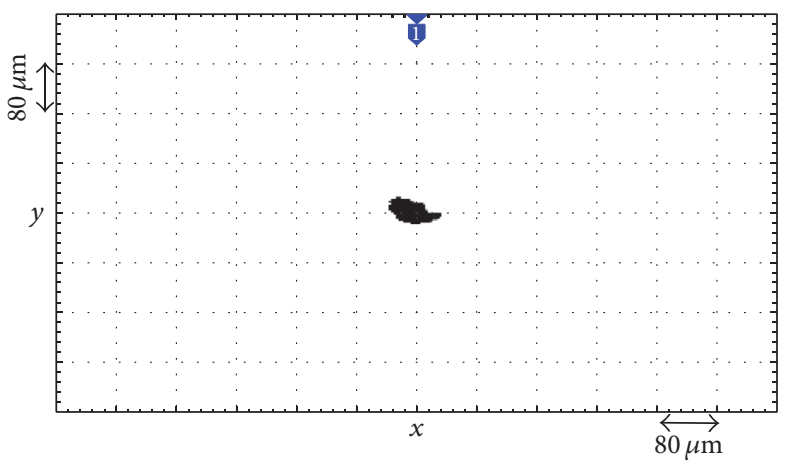

(a)

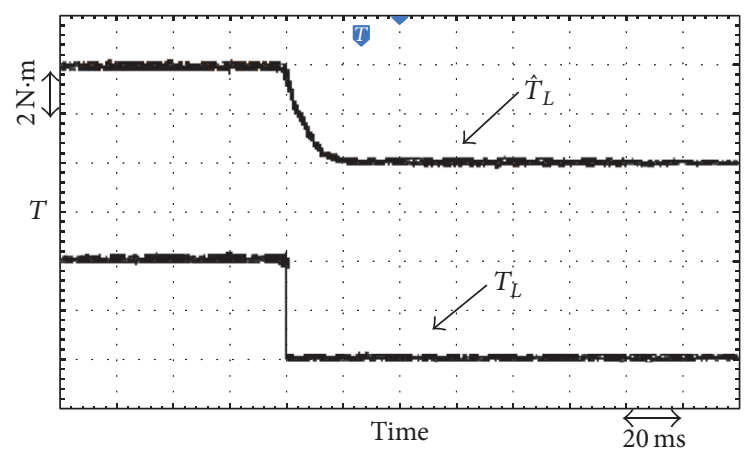

(c)

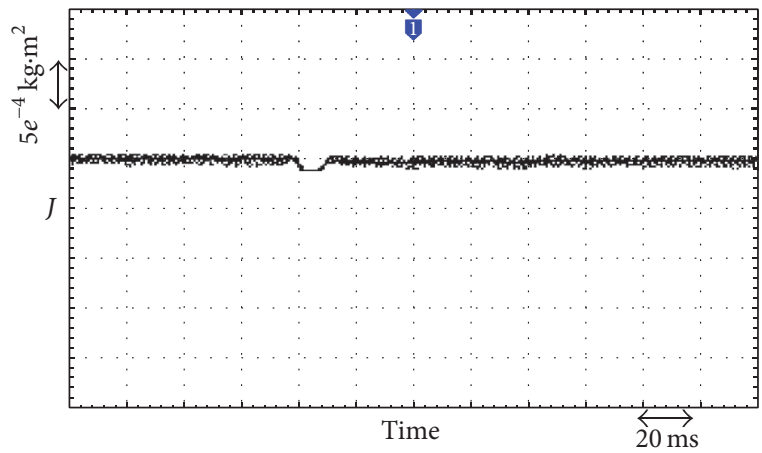

(b)

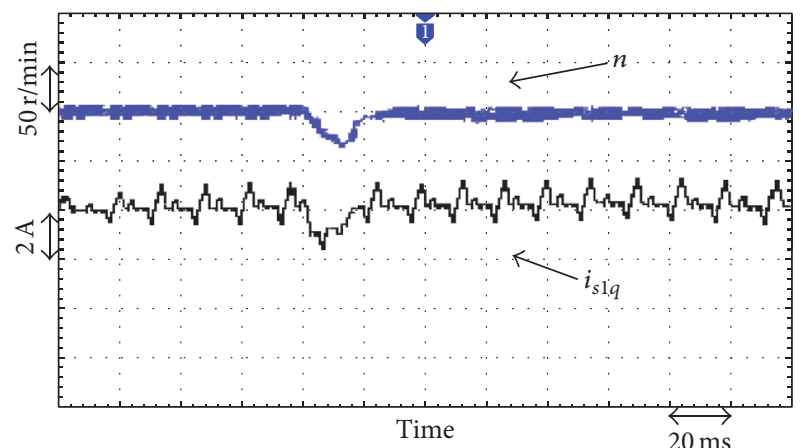

(d)

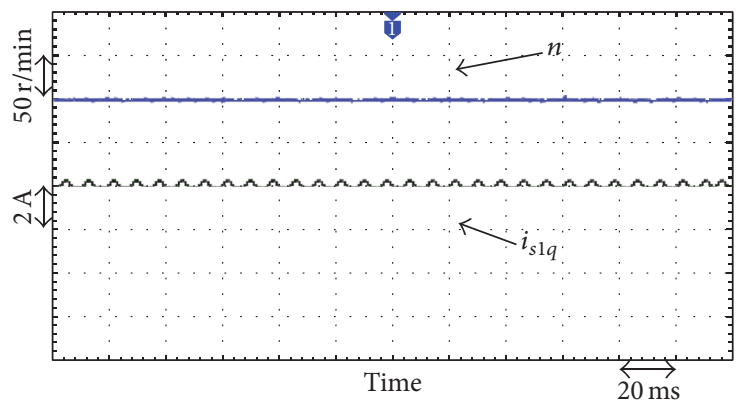

(e)

FIGURE 8: The experimental waveforms underload mutation: (a) the radial displacement of rotor; (b) the identification results of rotational inertia under load mutation; (c) the waveforms of torque; (d) the responses of speed and current under the conventional SMC; and (e) the responses of speed and current under the proposed method.

rotational inertia returns back to the stable value after a slight fluctuation. The observing waveform of load torque is given in Figure 8(c). It can be seen from the waveform that the sliding mode observer tracks the load precisely. Figures $8(\mathrm{~d})$ and 8(e) present the experimental results based on the control strategy of ordinary SMC and the proposed method in this paper separately. From Figure 8(d), it can be found that the current has big undulation. The speed decreases by $40 \mathrm{r} / \mathrm{min}$ and needs $20 \mathrm{~ms}$ to restore stability. From Figure 8(e), the load mutation does not affect the output of SMC and the speed is smooth. By comparing (d) with (e), it can be found that using the new load torque sliding mode observer and the feedforward compensation scheme can make BIM exactly and stably operate. In addition, it has low sensitivity with respect to disturbances.

\section{Conclusions}

A novel load torque sliding mode observer was proposed to eliminate the adverse impacts caused by load disturbance in BIM control system. Owning to the application of a lowpass filter in the sliding mode observer, the observation error of load torque is effectively reduced. At the same time, the output of load torque observer as disturbance compensation greatly diminishes the amplitude of discrete quantity and weakens chattering. With the integral identification method, the proposed sliding mode observer can identify the rotational inertia accurately and improve the robustness of rotational inertia for disturbances. The simulation and experimental results all show that the proposed control scheme in this paper effectively improves the dynamic and 
static performance of BIM control system, suppresses the system chattering, and enhances the robustness of system.

\section{Competing Interests}

The authors declare no conflict of interests.

\section{Authors' Contributions}

Zebin Yang and Ling Wan proposed the new idea of sliding mode control for Bearingless Induction Motor based on a novel load torque observer. Ling Wan derived the equations. Xiaodong Sun established the simulation model. Lin Chen was in charge of analyzing the data. Zheng Chen checked the language. All authors were involved in preparing the manuscript.

\section{Acknowledgments}

This work was supported by the National Natural Science Foundation of China under Projects 51475214, 61104016, and 51305170, the China Postdoctoral Science Foundation Funded Project 2015T80508, the Natural Science Foundation of Jiangsu Province of China under Projects BK20130515, BK20141301, and BK20150524, the Professional Research Foundation for Advanced Talents of Jiangsu University under Projects 12JDG057 and 14JDG076, Six Talent Peaks of Jiangsu Province under Projects ZBZZ-017 and 2015-XNYQC-003, and the Priority Academic Program Development (PAPD) of Jiangsu Higher Education Institutions.

\section{References}

[1] T. Hiromi, T. Katou, A. Chiba, M. A. Rahman, and T. Fukao, "A novel magnetic suspension-force compensation in bearingless induction-motor drive with squirrel-cage rotor," IEEE Transactions on Industry Applications, vol. 43, no. 1, pp. 66-76, 2007.

[2] X. Sun, L. Chen, and Z. Yang, "Overview of bearingless permanent-magnet synchronous motors," IEEE Transactions on Industrial Electronics, vol. 60, no. 12, pp. 5528-5538, 2013.

[3] E. F. Rodriguez and J. A. Santisteban, "An improved control system for a split winding bearingless induction motor," IEEE Transactions on Industrial Electronics, vol. 58, no. 8, pp. 34013408, 2011.

[4] X. Sun, L. Chen, H. Jiang, Z. Yang, J. Chen, and W. Zhang, "High-performance control for a bearingless permanent magnet synchronous motor using neural network inverse scheme plus internal model controllers," IEEE Transactions on Industrial Electronics, vol. 63, no. 6, pp. 3479-3488, 2016.

[5] A. T. De Almeida, F. J. T. E. Ferreira, and A. Q. Duarte, "Technical and economical considerations on super highefficiency three-phase motors," IEEE Transactions on Industry Applications, vol. 50, no. 2, pp. 1274-1285, 2014.

[6] X. Sun, L. Chen, Z. Yang, and H. Zhu, "Speed-sensorless vector control of a bearingless induction motor with artificial neural network inverse speed observer," IEEE/ASME Transactions on Mechatronics, vol. 18, no. 4, pp. 1357-1366, 2013.

[7] Z. Yang, D. Dong, R. Fan, X. Sun, and R. Jin, "Radial displacement-sensorless control for bearingless induction motor," Journal of Beijing University of Aeronautics and Astronautics, vol. 41, no. 8, pp. 1388-1395, 2015.

[8] T. Schuhmann, W. Hofmann, and R. Werner, "Improving operational performance of active magnetic bearings using Kalman filter and state feedback control," IEEE Transactions on Industrial Electronics, vol. 59, no. 2, pp. 821-829, 2012.

[9] Z. Yang, D. Dong, H. Gao, X. Sun, R. Fan, and H. Zhu, "Rotor mass eccentricity vibration compensation control in bearingless induction motor," Advances in Mechanical Engineering, vol. 7, no. 1, Article ID 168428, 2015.

[10] B.-J. Hou, J.-S. Gao, X.-Q. Li, and Y.-F. Zhou, "Study on repetitive PID control of linear motor in wafer stage of lithography," Procedia Engineering, vol. 29, pp. 3863-3867, 2012.

[11] C.-K. Lai and K.-K. Shyu, "A novel motor drive design for incremental motion system via sliding-mode control method," IEEE Transactions on Industrial Electronics, vol. 52, no. 2, pp. 499-507, 2005.

[12] Z. Yang, L. Wan, X. Sun, F. Li, and L. Chen, "Sliding mode variable structure control of a bearingless induction motor based on a novel reaching law," Energies, vol. 9, no. 6, p. 452, 2016.

[13] K. J. Lin, "Sliding mode control design for uncertain singular systems," Applied Mechanics \& Materials, vol. 145, no. 8, pp. 1620, 2011.

[14] S. J. Zhu, Y. P. He, and J. Ren, "Design of vehicle active suspension system using discrete-time sliding mode control with parallel genetic algorithm," in Proceedings of the ASME International Mechanical Engineering Congress and Exposition (IMECE '13), 8 pages, November 2013.

[15] Y. Chu and J. Fei, "Adaptive global sliding mode control for MEMS gyroscope using RBF neural network," Mathematical Problems in Engineering, vol. 2015, Article ID 403180, 9 pages, 2015.

[16] X. G. Zhang, K. Zhao, L. Sun, and Q. An, "Sliding mode control of permanent magnet synchronous motor based on a novel exponential reaching law," Proceedings of the Chinese Society of Electrical Engineering, vol. 31, no. 15, pp. 47-52, 2011.

[17] R. Li, G. Y. Zhao, and S. J. Xu, "Sensorless control of permanent magnet synchronous motor based on extended sliding mode observer," Transactions of China Electrotechnical Society, vol. 3, pp. 79-85, 2012.

[18] M.-H. Wang, M.-L. Huang, and W.-J. Jiang, "Maximum power point tracking and harmonic reducing control method for generator-based exercise equipment," Energies, vol. 9, no. 2, article 103, pp. 1-13, 2016.

[19] H. Q. Hou, Q. Miao, Q. H. Gao, and B. T. Aorue, "Fuzzy backstepping sliding mode control for mismatched uncertain system," Journal of Engineering Science and Technology Review, vol. 7, no. 2, pp. 175-181, 2014.

[20] J. J. Zhu, M. Su, X. Z. Wang, and L. Ma, "Direct-torque-control of brushless DC motors based on segmented sliding-modevariable-structure," Chinese Journal of Scientific Instrument, vol. 34, no. 11, pp. 2634-2640, 2013.

[21] Z.-C. Qiu, J.-L. Guo, B. Wang, and J. Xiao, "Deadbeat predictive current control based on a sliding mode observer with Kalman filter for PMSM speed and rotor position," Electric Machines and Control, vol. 18, no. 4, pp. 60-65, 2014 (Chinese).

[22] Y.-M. Fang, Z. Li, Y.-Y. Wu, and X. Yu, "Backstepping control of PMSM position systems based on terminal-sliding-mode load observer," Electric Machines and Control, vol. 18, no. 9, pp. 105111, 2014 (Chinese). 
[23] K.-J. Lin, "Adaptive sliding mode control design for a class of uncertain singularly perturbed nonlinear systems," International Journal of Control, vol. 87, no. 2, pp. 432-439, 2014.

[24] X. G. Zhang, L. Sun, and K. Zhao, "Sliding mode control of PMSM based on a novel load torque sliding mode observer," Proceedings of the Chinese Society of Electrical Engineering, vol. 32, no. 3, pp. 111-116, 2012 (Chinese).

[25] Z. Li, G. D. Hu, J. R. Cui, and G. Cui, "Sliding-mode variable structure control with integral action for permanent magnet synchronous motor," Proceedings of the Chinese Society of Electrical Engineering, vol. 34, no. 3, pp. 431-437, 2014. 


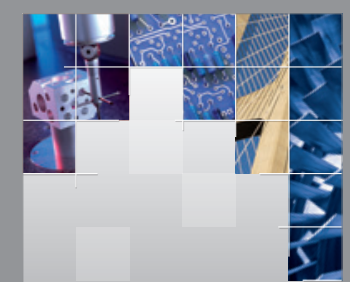

\section{Enfincering}
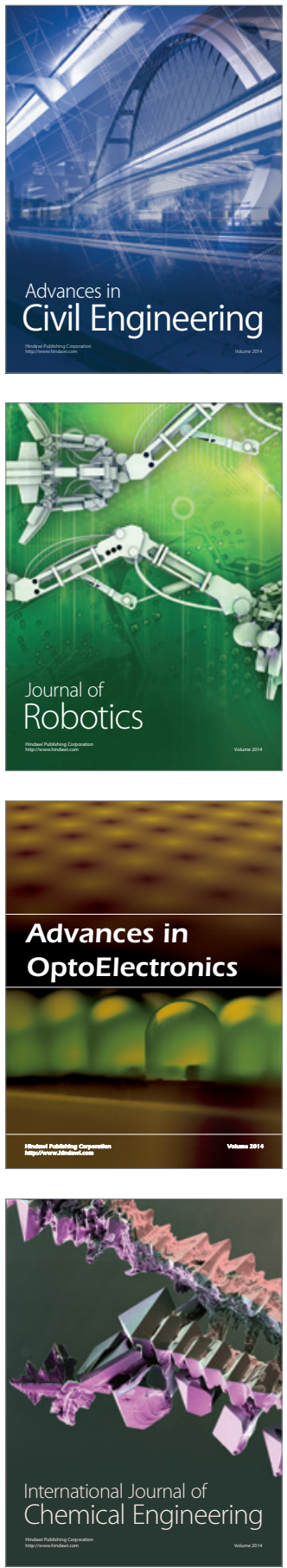

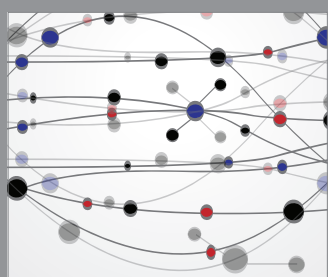

The Scientific World Journal

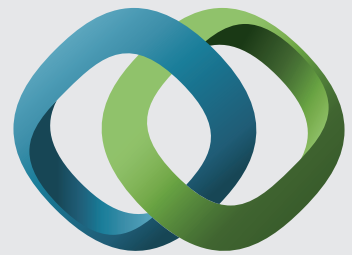

\section{Hindawi}

Submit your manuscripts at

http://www.hindawi.com
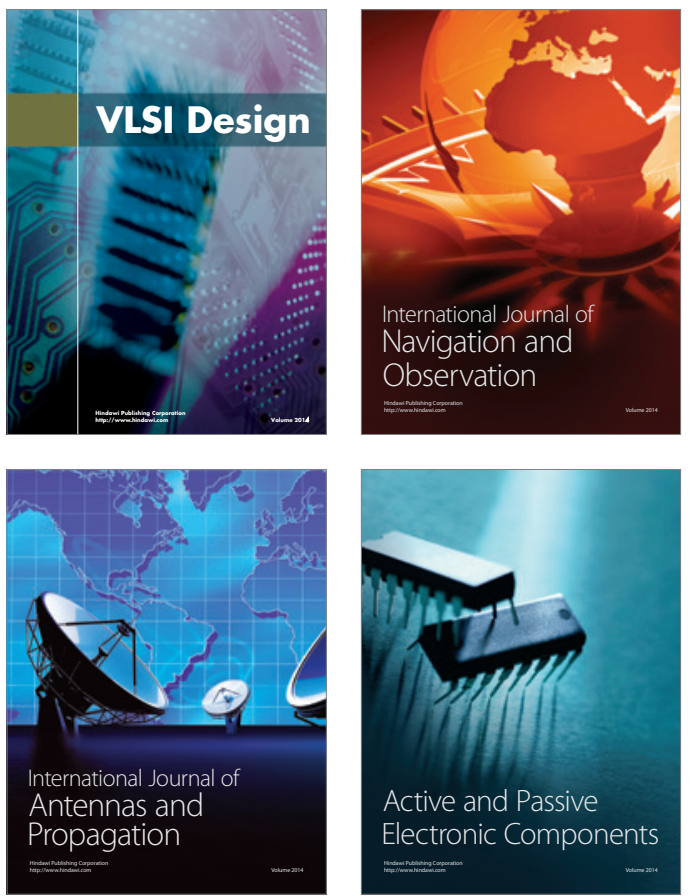
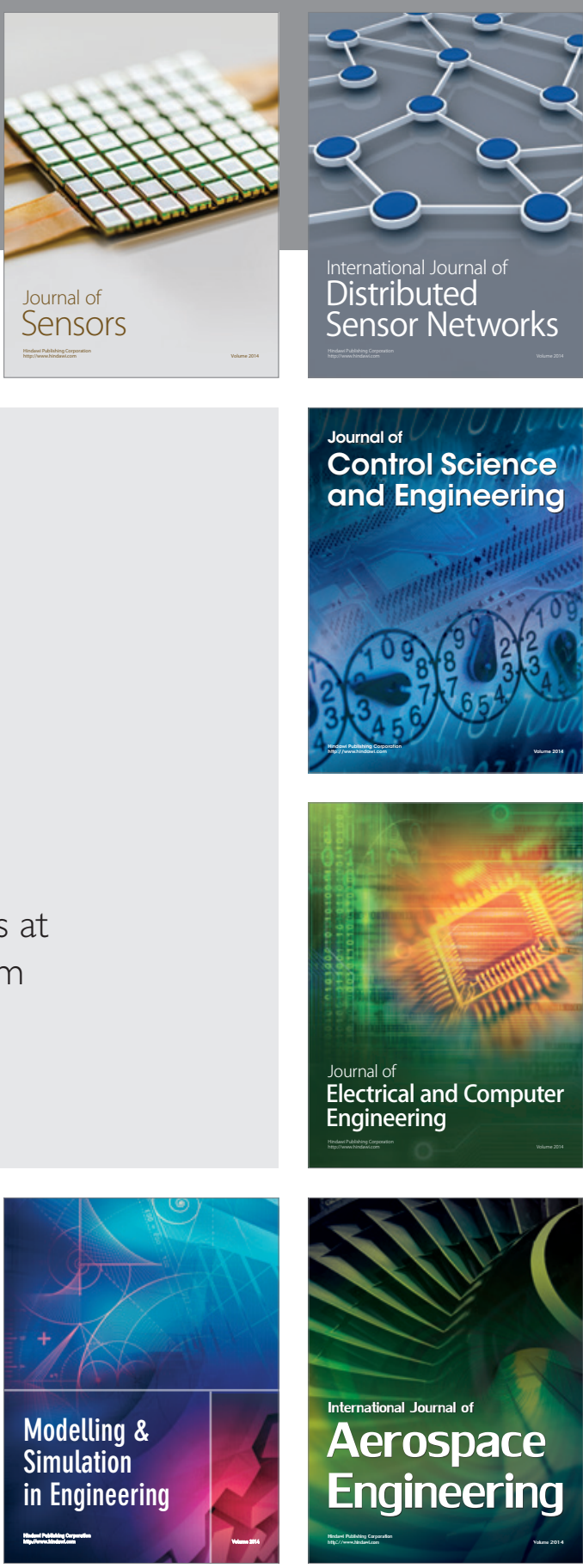

International Journal of

Distributed

Sensor Networks

Journal of

Control Science

and Engineering
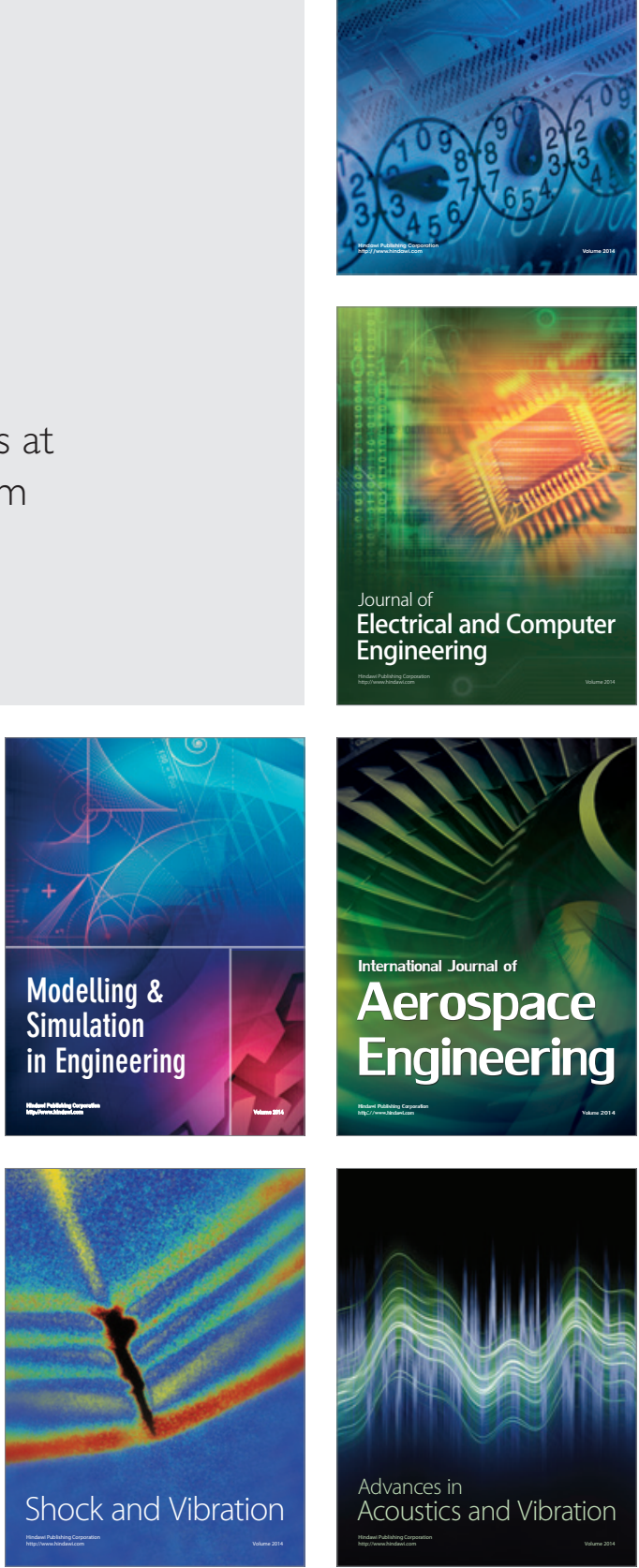